\title{
LA GOBERNABILIDAD CENTROAMERICANA EN LOS NOVENTA \\ Consideraciones sobre las posibilidades democráticas en la postguerra
}

\author{
Edelberto Torres Rivas*
}

El propio título de este trabajo limita el objeto de esta reflexión en tanto sólo para tres países de la región se puede hablar del "fin de la guerra". Es una manera de introducirnos a preguntas claves como las siguientes. ¿Son gobernables las sociedades que se alejan de la violencia política y la guerra? Y, entonces, ¿se puede hablar en efecto de un período de postguerra en Nicaragua, El Salvador y Guatemala? ¿Puede construirse la democracia política con movimientos populares derrotados, o que no triunfaron, o que transaron? ¿Pueden convivir la democracia política con la pobreza social? ¿Cuáles son los nuevos aspecto de la actual situación centroamericana? Las siguientes son un conjunto de reflexiones, a manera de balbuceos de respuesta acerca de las nuevas experiencias políticas en la región.

\section{DE LAS HERENCIAS DEL PASADO, LA VIOLENCIA}

La situación de Centroamérica no ha sido homogénea en su conformación como sociedades nacionales. En la dimensión política reciente encontramos, dicho con afán de sintesis, tres situaciones diversas:

a) La democracia burguesa o liberal en Costa Rica, madura y maciza a lo largo del último medio siglo de democracia moderna, que logró la hazaña múltiple de abolir el ejército, crear una sociedad política consensual apoyada en una sociedad clasista no polarizada, con instituciones estatales que garantizan tanto la honestidad electoral como una buena dosis de responsabilidad social, recostados en una tradición liberal que privilegia el orden y la estabilidad, en detrimento del activismo popular, por intermedio de un Estado, a lo clásico, en cuyo interior se resuelven los conflictos de clase y que gana legitimidad permanente por la fuerza de sus políticas sociales. Las elecciones, reificadas por el sentido común, no son las que hacen democrática esta sociedad, pues el sufragio lo que califica, cuando es libre y abierto, es la democracia política. El sustento vigoroso de

(*) Profesor en la Universidad de Costa Rica. esta última, es la extraordinaria calidad igualitaria, permisiva, tolerante, de las relaciones interpersonales cotidianas, la ausencia de aristas en la estratificación clasista, una cultura democrática, cívica, que todavía se apoya en los ecos del mito de que ésta es o fue una sociedad de campesinos.

b) La democracia vigilada, en Guatemala, El Salvador, Honduras, corresponde a la modalidad de transición de dictaduras militares institucionales que han sido sustituidas, a medias, por gobiernos civiles electos. La centralidad militar como factor político libre-de-todo-examen (hasta hace poco) se origina y se explica, en estas sociedades desarticuladas, porque constituyen la única institución con una presencia activa y nacional, con una organización jerárquica dura que resuelve sus diferencias internamente, movilizando una ideología unificadora hoy día a la defensiva, pero que incluye al mismo tiempo una misión histórica autodefini$\mathrm{da}(1)$, es decir, un sentido trascendente de sus funciones. Los gobiernos civiles constituyen la expresión de un arreglo implícito entre generales y empresarios, vía democracia electoral, un pacto de oportunidad que malgré tout, requiere de los partidos políticos y de alguna forma de participación social. Todo esto en sociedades profundamente desiguales, tanto por el reclamo exitoso de los grupos propietarios como porque las políticas del Estado han sido ejecutadas explícitamente para la protección de tales intereses.

c) Y la democracia difícil, que funciona en una sociedad como Nicaragua, que se ha conformado en la historia de este siglo con fragmentaciones políticas y guerras civiles e intervenciones de los Estados Unidos. Los Nicaragüenses heredan dos tradiciones antidemocráticas recientes, el sentido del orden de la dictadura somocista y el sentido del cambio de la revolución sandinista(2)

(1) La sociología militar en Centroamérica continuará dando vuletas en redondo si no se beneficia del enfoque histórico que puede contribuir a explicar la permanente centralidad militar y el fuerte sentido mesiánico del comportamiento de sus élites.

(2) El tema de la naturaleza democrática del sandimos, que ya se debate hoy en día pero aún con sesgos, no es nuestro objeto aquí. Lo antodemocrático se refiere a la necesidad defensiva de toda revolución, sobre todo en sus primeros tiempos, de concentrar el poder; en el caso del sandinismo, además no favoreció su carácter democrático, la inmediata experiencia militar trasladada a la administración del Estado. para el 
Nos interesa argumentar el tema de la gobernabilidad en relación con tres de estos países. Las elecciones Constituyentes y Presidenciales no marcaron en ellos el fin de gobiernos autoritarios sino que inician la gradual modificación de los mismos en un sentido que en otros momentos hemos llamado transición democrática por vía autoritaria, porque están presentes casi todos los componentes del sistema político del período anterior, y porque la convocatoria y el proceso se realiza bajo la égida militar. Es decir, bajo su protección y con su garantía.

En la medida que están presentes los componentes del período militar autoritario que giran en torno a la contrainsurgencia, la violencia es el elementos más difícil de expulsar de la vida política. Las exclusiones sociales se mantienen en parte y la vida misma, castigada por la pobreza, configuran una situación realmente compleja para la construcción de los consensos democráticos. Las elecciones han empezado a ser libres y honestas, pero la sociedad misma no favorece estas cualidades, a) porque sólo participan partidos conservadores o de centro derecha; b) porque la violencia política y el terror anulan diversas formas de participación; y c) porque los efectos generacionales de la terrible pobreza debilitan al máximo la condición ciudadana, estableciendo los límites de la paradoja de democracia sin prosperidad.

La experiencia múltiple de estos años habla de transiciones incompletas por la herencia de residuos autoritarios en el sistema política. No nos referimos al carácter no democrático de la vida social y económica marcada por profundas diferencias sociales y por mecanismos culturales que las justifican y reproducen. Estamos pensando en el sistema político en formación, donde el foco disruptivo de la estabilidad democrática es la falta de sumisión del poder militar al poder civil. El Ejército forma parte del gobierno, "penetra" la administración pública de varias maneras, comparte el ejercicio del poder como resultado de viejas rutinas y de la actual conformación del Estado.

No habría que olvidar que estas sociedades fueron conformadas o penetradas en profundidad por una cultura que premia y respeta al más fuerte, al más violento o arbitrario, y les perdona en función de la estratificación social. La intolerancia define de manera particularmente estrecha al contrincante, que se percibe entonces como enemigo, con diversos grados de peligrosidad con quien no hay que competir sino combatir. Fuerza e intolerancia se mezclan en todos los niveles de la vida social aunque en el nivel de las apariencias políticas, las elecciones, la competencia partidaria y la polémica en los medios, parecieran que se han terminado.

La transición, en esta óptica, no ha terminado. La consolidación democrática estaría asociada a altos niveles de gobernabilidad, a partir de nuevas formas de articulación entre el poder político —el Estado- y las organizaciones sociales - de la sociedad civil-. El Estado de derecho, primera condición de la gobernabilidad, no existe

examen de la experiencia somocista la bibliografía es abundante y llamo la atención acerca del reciente trabajo de Knut Walter, The Regime of Anastasio Somoza (19361956), The University of North Carolina Press, Chapel Hill, 1993. como legalidad vigente en el ámbito nacional mientras se mantengan las violaciones a los derechos humanos más elementales. Las libertades públicas son ejercitadas sólo por unos pocos, bien colocados en la pirámide social. La democracia política es centrífuga y excluyente, desde arriba y desde el centro y por ahora funcional para la élite empresarial y partidaria y útil para los líderes populares reformistas que le confían para encontrar por la vía pacífica y legal lo que con la lucha armada fracasó.

La teoría de la transición no sirve para explicar lo que realmente sucede en experiencias como las de Guatemala y El Salvador, aunque probablemente es más pertinente para Honduras. Lo que ocurre en los dos primeros países no es transición a, sino coexistencia de componentes democráticos en un contexto social definido por las relaciones de subordinación autoritaria del período de la dictadura. No son los escombros del período autoritario los que persisten, sino sus instituciones, normas, relaciones sociales, valores, cultura, etc. Esa coexistencia se produce, por ejemplo, con todo lo que tiene que ver con la administración de la justicia: el Poder Judicial, los Magistrados y Jueces, los funcionarios menores y sus prácticas, mezcla de corrupción y miedo, la policía, las cárceles, la investigación judicial, etc.(3)

Esto es importante porque toda actividad definida como afín a la insurrección es castigada brutalmente. Es irrisorio hablar de residuos autoritarios, porque la violencia es parte del mandato político. La eficacia del mandado, en una sociedad lastimada por la guerra es que los efectos de la misma ya no se perciben como anormalidad. Un poder consensual rechaza la violencia y por ello, la eficacia de la democracia es que evita su uso o lo reduce al mínimo.

La democracia en estos países enfrenta pues el dilema de las relaciones entre el poder y la violencia, relaciones que las sociedad autoritarias resuelven confundiendo ambos momentos. Es necesario distinguirlos analíticamente porque como lo enseña la tradición teórica, que Weber llevó a su forma conspicua, la identificación se realiza distinguiendo la violencia legítima como monopolio del Estado y por lo tanto, como atributo que lo define.

Queda la duda factual de qué clase de violencia es la ilegítima, si es legítima la violencia que aplica un Estado ilegítimo y cómo se resuelve la relación en situaciones de guerra civil. La coexistencia de formas democráticas y autoritarias, elecciones y guerra, ombudsman y persistentes ejecuciones sumarias, etc., en la década de los ochenta en Centroamérica ocurre en el interior de estos parámetros: violencia ilegítima aplicada por gobiernos que intentan legitimarse a través de las elecciones. Gobiernos civiles que toleran la impunidad militar. Y es que la violencia es más una agresión a los derechos humanos que a los políticos. Es una violencia total, sin llegar a ser totalitaria, porque se atenta permanentemente contra el derecho a la vida.

(3) Y por supuesto, aunque sea harina del mismo costal, es autoritaria la vida en la hacienda y la empresa, en la escuela y en el hospital, en el seno familiar y en todos los sitios donde se experimenta alguna forma de poder. La democracia de elecciones y oportunidades debe extenderse a todos los lugares en que como estos se practican la subordinación forzada, la arbitrariedad, el irrespeto a los derechos humanos. 


\section{LA GOBERNABILIDAD COMO CONDICION DEMOCRATICA}

El tema de la gobernabilidad es pertinente porque al igual que ocurre en numerosas sociedades latinoamericanas, a las experiencias de gobiernos civiles electos en procesos libres y competitivos en los ochenta, las ha empezado a acompañar una extendida desilusión pública, en los noventa. La democracia política en algunas sociedades centroamericanas se ha vivido sólo como experiencia electoral, sin seguridad ciudadana pero con posibilidades ciertas de participación social. Con esperanzas de corto plazo, empieza a surgir un explicable incipiente desengaño colectivo, que como mecanismo de compensación - lo dice la sicología social- ocurre cuando el conocimiento de la verdad nos saca tarde o temprano de la mentira. ¿Qué se le debe exigir razonablemente a la democracia política?

El tema de la gobernabilidad es en nuestro medio, gobernabilidad democrática. $Y$ queda constituida como desafío a raíz de la convergencia de dos conjuntos de fenómenos sociales. Uno, la necesidad de asegurar el orden y la estabilidad sin violencia política cuando se está dejando atrás, con dificultades, un terrible período de crisis y guerra. Otro, la necesidad de producir resultados visibles en la lucha contra la pobreza a partir de las carencias que se heredan del período anterior. En consecuencia, la gobernabilidad apunta a los problemas del orden social y a los de la productividad democrática. Ambos, objetivos difíciles de alcanzar en el corto plazo en sociedades con hondas raíces autoritarias y cuyos habitantes experimentaron durante más de una década la profunda desorganización de sus vidas. La crisis y la guerra son formas totales de desajuste colectivo, trastorno en las normas y en las conductas, que producen en consecuencia la creencia en que la irregularidad es la normalidad de la vida.

La primera cuestión a partir de lo anterior, es recordar, en consecuencia, que la democracia no es un fin en sí mismo, sino un medio para alcanzar la convivencia política civilizada, y además, el crecimiento económico con formas equitativas en la producción/reparto de la riqueza social. $\mathrm{Ni}$ los más duros politólogos "institucionalistas" dejan de referirse a la necesaria articulación entre los logros de la democracia política y las urgencias de la democracia económica. Considerando las frustrantes experiencias de las dictaduras militares centroamericanas, con la excepción aún más negativa en el caso de Somoza, que estancaron estas sociedades so pretexto del orden y del anticomunismo, afirmamos que sólo bajo un régimen de democracia política pueden enfrentarse exitosamente las tareas de la reconstrucción de Centroamérica.

La experiencia centroamericana es aleccionadora en la naturaleza de las relaciones entre la democracia/dictadura y el crecimiento/estancamiento económico. La única democracia de la región, Costa Rica, tiene elevados indicadores económico-sociales que la ubican en el tercer lugar en el índice de Desarrollo Humano (en América Latina) y es, sin ninguna duda, una sociedad bien administrada. Nicaragua, que bajo la estirpe Somoza padeció la peor dictadura lati- noamericana, es una de las sociedades más retrasadas de la región, situación que el sandinismo no pudo superar. La relación entre régimen político y crecimiento económico es objeto de vivo debate hoy día, y aún más, centrado en si la democracia política promueve o retarda la modernización económico-social. La prueba histórica es contradictoria y desorientadora y la conclusión de una reciente revisión de la bibliografía es que las instituciones políticas influyen en el crecimiento económico, pero no es posible encontrar diferencias relevantes entre regímenes políticos(4).

Pero no hay espacios para la duda de que hoy día, para fortalecer la democracia electoral en Centroamérica es necesario, además, un buen gobierno. En efecto, la democracia política asegura que las reglas de la elección se han cumplido y que el pueblo ha podido decidir. Pero una elección democrática no garantiza un gobierno competente, es decir, con responsabilidad pública, con eficiencia para atender los graves problemas sociales heredados, con funcionarios honrados, cuyo manejo reproduzca confianza y credibilidad. El buen gobierno, como metáfora, alude en consecuencia a un estilo ético, técnico y político que busca favorecer a las masas ciudadanas, en condiciones de democracia electoral.

Esta es una manera de plantear los dos aspectos claves que se refieren a la gobernabilidad de la sociedad, es decir, el tema de la legitimidad y el de la eficiencia(5). De hecho, en Centroamérica, muchas de las diversas causas que provocaron la inestabilidad y la crisis y que volvieron ingobernables estas sociedades, desafortunadamente, no han desaparecido y tienen que ver con la legitimidad y la eficacia. Muchos de esos factores, aunque cambiaron las circunstancias que las potenciaron y les dieron ocasión de manifestarse, permanecen en amenazante vigilia. Las mayores expresiones de esos factores pesaron tanto que una generación de nicaragüenses, guatemaltecos, salvadoreños, creímos que una causa justa podría ser alcanzada por intermedio de una guerra justa. Jus ad bellum, como cuestión vinculada a la legitimidad de la violencia para recomponer sociedades profundamente injustas.

Los sistemas administrativos, institucionales y políticos tradicionales quedaron debilitados o desacreditados por la crisis de los ochenta. Por lo tanto, las deficiencias de tales sistemas, en tanto ellos no se han modernizado son deficiencias para lograr umbrales aceptables de legitimidad y eficiencia para gobernar en las nuevas condiciones planteadas por el proceso de democratización. Gobernabilidad, en estas condiciones, es la cualidad del sistema político según la cual sus instituciones actúan eficientemente, de un

(4) Adam Przeworski y Fernando Limongi, "Regímenes Políticos e Crescimento Económico", en Novos Estudos CEBRAP, 37, Nov. 1993, págs. 174 y ss. El cuadro 1 del ensayo citado resumen 17 investigaciones estadísticas sobre el tema. La conclusión de un anterior trabajo de Przeworski es que las dictaduras en sociedades con nivel intermedio de crecimiento, lo hacen más rápidamente. Otros, más recientes, sobre muestras importantes de países en desarrollo, sugieren que la democracia es más favorable para el crecimiento económico.

(5) Este tema lo he tratado paralelamente en dos trabajos màs, "Amèrica Latina, gobernabilidad y democracia en sociedades en crisis", Nueva Sociedad, Nov.-Dic-, 1993, Caracas, y en "La gobernabilidad democrática y los partidos políticos en América Latina", a publicarse en una antología de CAPEL, San José, 1994. 
modo considerado legítimo por la ciudadanía, porque les proporcionan seguridad, integración y prosperidad, permitiendo el libre ejercicio de la voluntad política democrática del Estado, así como la participación de los ciudadanos, todo lo cual asegura el orden y la continuidad del sistema.

\section{SOBRE LA SOCIEDAD CIVIL Y EL ORDEN DEMOCRATICO}

En sociedades que experimentaron agudos períodos de desorganización social y estancamiento económico, con una crisis política que se situó en el seno mismo del Estado y no fue solamente un desarreglo pasajero de su sociedad política, el complejo de problemas que deben ser resueltos por los gobiernos civiles, recién electos, planea numerosos desafíos en el orden económico y político. Afirmamos que hoy día resulta prioritario consolidar las condiciones políticas necesarias para hacer frente a los otros problemas. Hay raíces de inestabilidad, en consecuencia, tanto en la dimensión estatal, donde lo del buen gobierno adquiere sentido(6), como en la dimensión de la sociedad civil, donde lo de la organización/participación social y política cobra relevancia. Sin asegurar estas cualidades el orden democrático que se está intentando crear, carecería de la fuerza necesaria para prosperar.

El orden en una sociedad depende de la manera cómo el Estado y sus Instituciones se organizan y dependen de la sociedad civil y de la manera cómo los problemas de ésta encuentran respuesta en las políticas del Estado. Se trata de una dicotomía provisional en el análisis en tanto referencia a las dimensiones política y económica-social, pública y privada que conforman la sociedad moderna, donde se diferencian y se vinculan, redefiniendo según la época sus fronteras fluidas. Una primera simplificación nos remite a la idea de que lo privado es lo económico y lo político es lo público; una segunda referencia sumaria reduce lo privado económico al mercado y lo público político al Estado.

Sin duda, el corazón del ámbito de lo privado es el mercado, donde se relacionan capitales competidores y capitalistas y asalariados, cuyo fin es maximizar la ganancia, que es privada. Tampoco hay duda de que el corazón del ámbito de lo público es el Estado como la suma de las instituciones territorializadas que mantienen el orden y asegurar la reproducción de la sociedad. El mundo mercantil, para que funcione con eficacia debe tener la protección y la garantía del poder del Estado, y éste no podría existir hoy día sin el mercado que le da base y lo determina. Pero es necesario agregar, para aliviar las simplificaciones, que no todo lo privado es mercaǹtil, así como no todo lo público es estatal.

(6) El problema del consenso que alimenta la legitimidad del Estado, tiene que ver con este del buen gobierno que hemos definidocomo una situación particular en que un gobierno democrático reciente, necesitả ratificar permanentemene su condición legítima para que la crisis de la política no traiga consigo el descrédito de la democracia. Y la única manera hoy día de ganar legitimidad cotidianamente es cumpliendo las metas propuestas, racionalizando los recursos disponibles, resolviendo cuestiones sociales, etc. Cf: E. Torres Rivas, "La democracia y la metáfora del Buen Gobierno", en Polémica, múm. 17, San José, 1993.
Con base en lo anterior, proponemos una definición restrictiva de lo que significa para nuestro propósito el ámbito de la sociedad civil que queremos destacar: es el ámbito de lo privado donde surgen los intereses sociales (no familiares) producto de las múltiples formas de la organización económica, intereses sociales cuya tendencia innata es a agruparse por afinidades, a organizarse de variadas maneras y como resultado natural de tal agrupación de intereses, a reivindicar, demandar, conflictuar como intereses colectivos. Esta dinámica privada tiene que ser independiente del poder del Estado y no estar vinculado directamente a la producción mercantil. Es importante agregar que lo contrario de colectivo en este caso no es lo individual, sino lo que no tiene sentido de comunidad. Se trata de trascender el fuero privado individual y convertir los intereses sociales privados organizados en intereses colectivos públicos. Así, y sólo así, se vuelven políticos, lo que está en el interés del orden democrático.

El movimiento de lo individual privado a lo colectivo públicado, esencia y expresión de la participación popular, es un resultado complejo de la relaciones entre el Estado y su peculiar naturaleza histórica y la correspondiente de la sociedad civil. Cuando esa sociedad es democrática, el poder estatal no sólo estimula y garantiza sino responde en su actuación a las múltiples determinaciones que fluyen de la sociedad civil. El desarrollo económico probablemente camina más rápido si esta articulación funciona así y son varias las maneras cómo esto se produce.

También debemos referirnos a otra dimensión fáctica y conceptual, la distinción de lo que se llama sociedad política cuya expresión primaria, dinámica, la constituye la existencia de partidos políticos y un espacio estable para su competencia, que realizan como es bien sabido funciones de intermediación y representación entre la sociedad civil y el Estado. Su extraordinaria importancia reside en que la modalidad partido político, que es una forma de organización de los múltiples intereses privados (en sentido lato), representa de manera unitaria esa multiplicidad en el espacio público. El partido moderno, organiza la diversidad social y la unifica en la representación política, sirviendo como forma orgánica de mediación, y, además, como recurso del orden y la integración de la sociedad.

Pero la participación popular no se agota en la participación partidario-política, aunque es su forma conspicua. Desde la sociedad civil se pueden agrupar los intereses privados organizados en sindicatos, cámaras patronales, asociaciones culturales, deportivas, barriales, de género, raza o religión, etcétera, etcétera. Desde el ámbito de lo privado, las organizaciones sociales, sus intereses y reivindicaciones, necesitan alcanzar una especificidad política para que puedan tener eficacia y éxito y esa especificidad se logra cuando se manifiestan en los espacios públicos. La dimensión pública es condición de eficacia política, sobre todo si su referente final es el Estado. En resumen, la organización de los intereses privados es requisito para que éstos superen tal condición, porque al volverse colectivos pueden alcanzar expresión pública, transformándose. Esta es la otra dimensión de la participación popular. En una democracia, no sólo 
los partidos políticos pueden hacer política; deben hacerla las organización sociales, a su manera, y de hecho la hacen cuando influyen, determinan, condicionan las políticas estatales.

En el tema de la gobernabilidad democrática, en consecuencia, no todo depende de la eficiencia del Estado para responder, ni de los mecanismos para legitimarse, sino también de la manera cómo la sociedad civil organiza sus intereses particulares, cómo es capaz de dotarlos de sentido de comunidad y cómo los traslada con eficiencia, a través de los partidos y las organizaciones sociales, a los niveles públicos y políticos. Sin Partidos políticos la democracia no puede funcionar. Pero su complemento imprescindible es el vigor y las oportunidades de las organizaciones sociales, independientes del estado y capaces de contrarrestar las tendencias naturales "irreflexivas" del mercado o el poder estatal. Es éste el sentido cabal de la democracia política, de la sociedad democrática misma.

En las sociedad en proceso de democratización con coexistencias autoritarias, experimentando situaciones de postguerra, como algunas centroamericanas, las cosas no ocurrieron así. El juego partidario fue débil o sesgado por la presencia militar, que no compite como partido político pero lo sustituye como fuerza de gobierno, como factor de poder. Los gobiernos militares "descansaron" en la desmovilización social a la que atribuyen una fuerza desorganizadora del orden político(7). Estos antecedentes son especialmente significativos en El Salvador, Guatemala y Nicaragua, donde los problemas de gobernabilidad no solamente se originan en el funcionamiento deficiente del gobierno y sus cohortes burocráticas, sino en el comportamiento de los partidos políticos y las emergentes organizaciones sociales, que también dan su contribución negativa a la gobernabilidad democrática.

Ya dijimos que la violencia deslegitima el carácter democrático del régimen político. El poder en un régimen democrático obliga a la distinción ya aludida (en la primera parte de este ensayo), pues sólo así la fuerza y su uso en un Estado democrático podrá considerarse como legítimo porque se realiza con apego a la ley. La sociedad moderna está organizada para limitar cada vez más el uso de la fuerza y satisfacer los objetivos de orden a integración a través de mecanismos o instrumentos racionales y legítimos. Esta legitimidad descansa en el reconocimiento de la ciudadanía de que el orden es legal y, además, legítimo. Recordemos que esta última cualidad, de acuerdo con nuestra definición de gobernabilidad, la tiene el Estado que funciona eficientemente y controla la violencia legítima.

Hay otras fuentes de deslegitimación e ingobernabilidad: la heterogeneidad básica de las sociedades centroamericanas se ha acentuado notablemente y hoy día aparece magnificada la dimensión del atraso social, extendido al abismo in-

(7) El comunismo, la URSS, Cuba, etcétera, comoideología, fuerza política amenaza real, independientemente de su efectiva capacidad alternativa, fue un pretexto significativo y concluyente durante mucho tiempo. La insurgencia civil de los años ochenta, con recursos de violencia armada y programas radicales, atrajeron aún más el uso de la violencia estatal para ordenar. Todos esos fantasmas tienen que ser exorcisados ya. terior que separa la riqueza y la miseria de una sociedad aún más polarizada, destruida una parte importante de las fuerzas productivas y de la confianza colectiva. Pero, además, una ofensiva de múltiples faces del gran capital que aún no encuentra límites, un Estado desacreditado y debilitado, una economía que para estabilizarse se estancó y ahora crece con renovado estilo concentrador. Todo esto origina protestas y un reclamo inmediatista que la democracia política está lejos de poder resolver.

\section{ALGUNAS EXPERIENCIAS DE INGOBERNABILIDAD}

No debería llamar la atención que las ciencias sociales se orienten hoy día de manera tan sostenida por los temas de la estabilidad y el orden político, porque se está saliendo en numerosas sociedades de atroces experiencias autoritarias, de movimientos revolucionarios que terminaron en la mesa de negociaciones y, en consecuencia, no dieron respuesta a las demandas que los justificaron. Todo esto alimenta las presiones sociales contenidas durante tantos años, que pueden finalmente expresarse en el nuevo clima democrático. Como demuestran algunos ejemplos recientes, los factores de ingobernabilidad aparecen por todos los poros de la sociedad.

a) La experiencia del orden alude a que las cosas ocupan el lugar que les corresponde en una situación de legalidad normal. El ejemplo que ofrece Nicaragua altera esa experiencia, antes, pero sobre todo ahora, cuando a partir del gobierno Chamorro las posibilidades de consenso democrático estaban objetivamente inscritas en los resultados electorales (febrero 1991). Lo que se ha ratificado es la imposibilidad para la estructuración de un sistema político, por la paradoja de partidos políticos con capacidad de organizar elecciones que no tienen capacidad para hacer gobierno. El país vive una crisis política permanente, lo cual conceptualmente es un contrasentido, a menos que se acepte que la anormalidad es la única forma de existencia de la vida política. Este es un ejemplo de ingobernabilidad originada por exceso de "partidismo", por los partidos políticos en un cuadro dominado por el canibalismo y la autofagia partidaria.

Los 14 partidos que apoyaron a la Sra. Chamorro y formaron la Unión Nacional Opositora (UNO), en una alianza contra natura desde el punto de vista ideológico y programático, por sus permanentes entreveros son prueba de fraccionamiento político y de reagrupamientos oportunistas. Una experiencia de pluralismo al revés. La primera señal de la crisis fue el conflicto con el Vicepresidente electo en la misma fórmula, Virgilio Godoy, que no ha podido ejercer el cargo. La sucesión de conflictos internos en la UNO son graves desavenencias superficiales, de la misma naturaleza de los conflictos que como partidos victoriosos pasaron a realizar, inmediatamente después del triunfo, pero ahora como oposición política.

Son luchas políticas intestinas por el poder, luchas políticas encerradas en sí mismas, por pedazos de un poder degradado por la crisis. En efecto, la crisis gira en torno a la exigencia de expulsión del Frente Sandinista, que aunque no 
es partido en el gobierno ha respaldado críticamente la gestión de la señora Chamorro. En una democracia política, las alianzas ciertamente se tejen y deshilan con cierta cadencia, apoyadas en estrategias cuya última ratio es el acceso al gobierno a través del procedimiento electoral. Una oposición que no puede esperar su oportunidad, no ha entendido las reglas de la democracia política.

Hacer política en estas condiciones se reduce a un activismo para no dejar gobernar, aumentar visiblemente el desorden desde lo estatal-institucional, en una situación de profunda descomposición social, tan grave como la que origina una desocupación reconocida del $60 \%$ de la PEA, en un decremento por cuarto año consecutivo del PIB, o se manifiesta en la conducta de Pedrito el hondureño. En su momento, fue éste un honorable mayor del Ejército Popular Sandinista, que al frente de 150 recompas (exsoldados sandinistas, levantados en armas) tomaron la ciudad de Esteli el 21 de julio de 1993, provocando muertos y asaltando bancos, con ánimo de hacerse justicia.

La acción de Pedrito el Hondureño es expresiva, en carne viva, de la descomposición que afecta a la nación: él y sus compañeros no pudieron ser reincorporados a la vida civil después de ser desmovilizados. El Estado no pudo cumplir con las ofertas que se hicieron a miles de combatientes, de ambos bandos, para absorberlos a la actividad productiva. De soldados a desocupados. La desesperación de la pobreza y la total ausencia de futuro alimentaron esta conducta anormal e inadmisible. La respuesta del Ejército, correlativo e esta historia aberrante, recuerda que el orden fue restablecido con un costo de 45 muertos y 98 heridos, nuevas destrucciones de infraestructura, en una operación militar que el gobierno calificó de exitosa. Semejante a tantas otras del resto de Centroamérica, que violentaron groseramente los derechos humanos.

Los enfrentamientos entre excombatientes y desmovilizados de la fuerza irregular conocida como Contras con el EPS han continuado sangrando física y financieramente al país exhausto. Una huelga del sistema de transportes, en septiembre de 1992, que dejó 12 millones de dólares en pérdidas, y muchas otras, ejemplifican cómo en la postguerra surgen exacerbadas las voluntades de participación desde la sociedad civil. El disenso recurrente y superficial, vuelto camorra entre los partidos políticos y el gobierno, la banalización de la protesta, no es ejercicio democrático. El viejo personalismo aparece entre los más pendencieros, y la UNO ha vuelto a dividirse al punto que de la vieja alianza electoral sólo quedan siete partidos(8) .

En algún momento calificamos la pugnacidad sin sentido nacional como el mal de Somalia, fenómeno propio del atraso político y que afecta a quienes, como señores de la guerra o jefes tribales, pelean por victorias personales a costa de la sociedad, de la nación misma. Hubo un jefe político que ha pedido la intervención de los Cascos Azules y

(8) La Coalición que integran a principios de enero de 1994, liberales y conservadores, comunistas, socialistas, socialcristianos y socialdemocráticas. ¿Qué denominación haría falta en una democracia electoral? Cf: La Nación, 12-1-94, pág. 22A. varios de ellos viajan a Washington para detener la magra ayuda que está obligado a darle al país que contribuyó a destruir. Sin ordenar la vida partidaria no habrá ni democracia ni desarrollo en Nicaragua, condiciones ambas para la gobernabilidad de un país.

b) Es propio de las situaciones de caos social la ruptura de los compromisos más elementales. La vida política de Guatemala, por múltiples razones bien conocidas, no logra salir de un largo período anómico que la afecta. Una situación de descomposición social que es necesario recordar porque es en esa perspectiva que debe analizarse la decisión del presidente Jorge Serrano Elías, de romper brutalmente la legalidad imperante, disolviendo los poderes contributivos del Estado y suspendiendo la Constitución de la República.

La crisis política tenía en mayo de 1993 cada vez más la forma extrema de la ingobernabilidad, que ocurre tanto en el interior del Estado como en el seno mismo de la sociedad. Es decir, que se manifiesta con una profunda inestabilidad en la manera imprevista y contradictoria como se realiza la participación social y política, en la desconfianza generalizada en las autoridades y en las instituciones representativa, en la proliferación de focos irrelevantes de descontento colectivo, en la parálisis del poder ejecutivo. Es decir, cuando ya no se manejan los resortes claves del sistema político.

Había algunos hechos claves que alimentaban la ingobernabilidad. Uno es la ruptura de la alianza política entre el partido del gobierno, el MAS, con las dos mayores fuerzas políticas en el Congreso, la Democracia cristiana y la Unión del Centro Democrático. Con esta sólida mayoría, Serrano pudo gobernar durante 18 meses con un buen margen de discrecionalidad. El fin de la alianza, a mediados de abril de 1994, dejó en una inesperada soledad política al gobierno.

Otro factor es el resultado de la contienda electoral del 9 de mayo (elección de 276 alcaldías), que exhibió la debilidad de la participación ciudadana y la falencia de los partidos políticos. Casi el 70\% de abstención es un crudo índice de desinterés masivo en la participación política, si no de un rechazo concertado como pareciera ser en ciertas áreas rurales. Aquí, los procesos electorales no consolidan el sistema. Por el contrario, los resultados mismos terminaron por desestructurar el partido más numeroso aunque no el mejor organizado del país, la Unión del Centro Democrático (UCN), y dejaron al partido más importante, la Democracia Cristiana, sólo con un $14 \%$ del voto.

Finalmente, fue una causa importante el descontento popular que en Guatemala se alimenta con razones elementales porque se alza sobre el piso de una lacerante pobreza social, se manifestó masivamente por diversos motivos y en distintos puntos del país. Desde finales de abril, como protesta por el alza de un $100 \%$ de las tarifas eléctricas. A partir de mayo, fueron los estudiantes de secundaria los que tomaron violentamente la calle, protestando por la decisión unilateral de utilizar un carnet de identificación para el uso del transporte público. Los estudiantes, una vez más, quemaron neumáticos y autobuses, lanzaron cócteles molotov, anormalizaron el tráfico en rechazo de algo que en cualquier sociedad normal se hubiera negociado rápida y directamente. 
En una sociedad ingobernable, la respuesta fue igualmente violenta y uno de los estudiantes, Abner Hernández, de 13 años, fue asesinado. En Guatemala, la manera de protestar, violenta $y$ agresiva, tiene su contrapartida magnificada en la manera de reprimir. $\mathrm{O}$, tal vez, a la inversa.

También el descontento de la población era desconfianza porque con este segundo gobierno civil fracasó la lucha contra la impunidad, que, dicho de manera elemental, es la capacidad del Estado de Derecho para castigar a los delincuentes. Los excesos cometidos por el Ejército durante dos generaciones han creado una cultura del miedo, y una privatización de la seguridad. Cuando se reclama contra la impunidad se apela a la obligación que tiene el Estado de aplicar sus propias normas. También fracasaron las pláticas entre el gobierno y la guerrilla, que debieron conducir, como ha ocurrido en más de una docena de experiencias internacionales, a la pacificación del país.

Tal vez la razón última de la ingobernabilidad es que la sociedad guatemalteca es una sociedad enferma. Largos años de violencia permanente, sistemática, multiforme, conocidos actos de corrupción, impunidad total para la delincuencia política, todo esto en un cuadro de pobreza extrema y de racismo exacerbado, etcétera, han vuelto débiles, poco confiables, dudosas, las instituciones políticas. Se ha formado un clima de disolución del orden en que todo es posible. Una decisión tan torpe como la del Presidente Serrano sólo puede producirse en una sociedad como ésta.

Las experiencias de la crisis forman parte de esta breve reflexión. Entre el autogolpe de Serrano, en la madrugada del 25 de mayo, y la elección de Ramiro León Carpio, el 5 de junio, se produjeron tres golpes de Estado sucesivos, pero también una extraordinaria y aleccionadora experiencia histórica. Una es que un autogolpe civil no se produce si no es también un golpe militar, como en parte lo fue. De otra manera no podría haber ocurrido. Otra, la constituyen las reacciones en el Congreso de la República, donde 50 diputados - faltaron 8 para constituir mayoría - casi ratifican la elección ilegal del vicepresidente Espina. Fueron golpistas por oportunismo, como muchos dirigentes de los partidos políticos. El Congreso no reaccionó como con el "fujimorazo" peruano y un sector del mismo estuvo dispuesto a transar. Por eso los grandes perdedores de esta crisis son los partidos políticos.
El ambiente que estimula la corta experiencia democrática animó algunos ánimos. Veamos dos ejemplos. Por un lado, fue sobresaliente la actuación de instituciones como la Corte de Constitucionalidad, que el 4 de junio rechazó las pretensiones del vicepresidente, también golpista, en sus intentos para suceder a Serrano. A su vez, el Procurador General de la República y Jefe del Ministerio Público, interpuso una demanda contra Serrano, Espina y Perdomo (ministro del Interior) por corrupción, violación del orden constitucional, rebelión, incitación pública, abuso de autoridad y otros delitos, todo lo cual permitió el respeto a la Constitución en el seno de la crisis.

El otro, fue la organización y convergencia de las más diversas fuerzas sociales en respaldo a la legalidad. La Instancia Nacional de Consenso, dirigida claramente por grandes empresarios, pero con algunos partidos y sindicatos, y la Multisectorial del Sector Social, con los mayores sindicatos, la Universidad y organizaciones religiosas, cooperativas e indígenas, movieron a la sociedad desde abajo en una expresión de hegemonía de la sociedad civil que la cúpula empresarial arrebató a los dirigentes políticos. La Corte de Constitucionalidad dio un plazo de 24 horas para elegir presidente y el Congreso, finalmente, eligió a Ramiro de León Carpio y a Arturo Herbruger, como presidente y vicepresidente respectivamente. La legalidad fue respetada y el nuevo presidente, apoyado por las organizaciones sociales de la sociedad civil, asumió con plena legalidad el cargo.

Este apoyo constituye un ejemplo particularmente útil de cómo operan los mecanismos de la legitimidad hoy día. Pero la ingobernabilidad guatemalteca sólo tuvo un respiro. El pulso entre el Ejecutivo y el Congreso tiene ya seis meses. Los elementos deslegitimadores aparecen de nuevo: corrupción e incompetencia en el cuerpo legislativo, indecisión e ineficiencia en el ejecutivo. La experiencia reciente podría resumirse como una crítica a los enemigos de la democracia que ella misma produce: en un ambiente de plena participación todos quieren participar al mismo tiempo por las mismas cosas. El resultado es el desorden.

La democracia burguesa, nos recuerda la teoría, es un método de adquirir poder resultado de una competencia pacífica entre élites. Es la calidad de esa competencia lo que está faltando. $\mathrm{Y}$ hay prisa por alcanzar la gobernabilidad democrática. Estas, son oportunidades que pueden perderse. 


\section{RESUMEN}

La reciente experiencia centroamericana, en especial en países que viven situaciones de postguerra como Nicaragua, El Salvador y Guatemala, pone en evidencia transiciones incompletas. Esto es debido a la coexistencia y permanencia de herencia autoritarias en el sistema político. La transición no habría terminado, ya que la consolidación democrática exigiría altos niveles de gobernabilidad eficiencia, legitimidad y libre ejercicio de la voluntad política y la participación ciudadana- sólo posibles con nuevas formas de articulación entre el poder político y la sociedad civil. De tal modo, se aseguraría orden, estabilidad y resultados en la lucha contra la pobreza. En definitiva, únicamente bajo un régimen de democracia política, con partidos políticos sólidos y una vida partidaria ordenada, podrían enfrentarse exitosamente las tareas de reconstrucción de Centroamérica.

ABSTRACT
Recent Centroamerican experience, specially in counstries which are in post-war situaciones such as
Nicaragua, EL Salvador and Guatemala, show not-finished transitions. The reason is the coexistence
and continuity of authoritarian heritages in political system. Transition hasn't finished because
democratic consolidation demands high level of governability -efficiency, legitimacy and free
exercise of political will and citizen participation- possible only with new ways of articulation
between political power and civil society. In this way, tidiness, stability and results will be guarantee
in fight agains poverty. Finally, only under political democratic regime, with solid political parties
and a tidy partitanship life, reconstruction of Centroamerica could be successful.

